\title{
STRATEGI PENGEMBANGAN KAWASAN MINAPOLITAN BERBASIS USAHA PEGARAMAN
}

\author{
Mei Dwi Erlina dan Manadiyanto \\ Balai Besar Penelitian Sosial Ekonomi Kelautan dan Perikanan \\ J. KS. Tubun Petamburan VI Jakarta 10260 \\ Telp. (021) 53650162, Fax. (021)53650159 \\ Email: mei_dwi_erlina@yahoo.com
}

Diterima 7 Mei 2012 - Disetujui 20 Juni 2012

\begin{abstract}
ABSTRAK
Kawasan Minapolitan harus memiliki 5 (lima) aspek dasar meliputi : 1).Subsistem Sumber daya dan Tata Ruang, termasuk teknologi, 2). Subsistem Masyarakat dan Bisnis, 3). Subsistem Kelembagaan, 4). Sub Sistem Kebijakan dan Governance, dan 5). Subsistem Infrastruktur. Tujuan penelitian ini adalah untuk melakukan pemetaan sentra produksi garam, mempelajari potensi dan kendala dalam pengembangan minapolitan berbasis usaha pegaraman, serta menentukan strategi pengembangan di lokasi usaha pegaraman. Pendekatan penelitian yang digunakan berupa studi kasus pada 19 lokasi Kabupaten/Kota. Perumusan strategi pengembangan kawasan minapolitan berbasis usaha pegaraman menggunakan metode analisis SWOT (Strength, Weakness, Opportunity and Threat). Hasil pengukuran indeks kesiapan pelaksanaan minapolitan pada 19 lokasi menunjukkan 2 lokasi dikategorikan sebagai kawasan mandiri, yaitu Kabupaten Pati dan Kabupaten Pamekasan dengan nilai indeks sebesar $80 \%$ dan $85 \%$. Kedua lokasi tersebut merupakan lokasi yang telah ditunjuk sebagai daerah sentra garam rakyat dan memiliki komitmen daerah yang tinggi dalam upaya pelaksanaan program minapolitan berbasis garam. Sedangkan 17 lokasi lainnya dikategorikan sebagai kawasan maju dalam pelaksanaan minapolitan dengan nilai indeks kesiapan berkisar antara 55\%-74\%. Strategi yang dirumuskan untuk kawasan minapolitan mandiri (Kabupaten Pamekasan) adalah "meningkatkan dukungan pemerintah melalui penyusunan regulasi mengenai harga jual garam ditingkat petambak garam". Strategi pengembangan minapolitan untuk Kabupaten Pati adalah "meningkatkan inovasi teknologi produksi garam untuk mengantisipasi anomali cuaca". Strategi yang dirumuskan untuk kawasan minapolitan maju adalah" memperbaiki fasilitas penyimpanan dan memberlakukan sistem resi gudang, melakukan pengawasan ketat terhadap masuknya garam impor, menetapkan standar kualitas garam yang jelas serta mengawasi harga dasar garam agar sesuai peraturan yang ditetapkan pemerintah".
\end{abstract}

Kata Kunci: strategi, pengembangan, kawasan minapolitan, usaha pegaraman

\section{Abstract: Minapolitan Area Development Strategy Based on Community Salt Business Institutions. By: Mei Dwi Erlina and Manadiyanto.}

Area of minapolitan should have 5 basic aspect includes : 1). Resources and spatial subsystem, including technology, 2). Public and business subsystem, 3). Institutional subsystem, 4). Policy and governance subsystem and 5). Infrastructure subsystem. The purpose of this study was to conduct mapping of salt production centers, studying the potential and constraints in the minapolitan development of based on Salt Business, and determine the development strategy of salt business. The research approach using case studies at 19 locations Regency / City. The formulation of the minapolitan development strategy based on salt business using SWOT analysis (Strength, Weakness, Opportunity and Threat). The results of readiness index measurements at 19 minapolitan locations, 2 showed the locations were categorized as 
independent, Pati and Pamekasan with index values of $80 \%$ and $85 \%$. Both of these locations were locations that have been designated as a regional center for the salt and have a high region commitment in an effort to implementing minapolitan program based on salt bussiness. While 17 other locations categorized as advanced in the implementation of the value minapolitan readiness index ranges between $55 \%-74 \%$. The strategy formulated for the minapolitan (Pamekasan) is "increasing government support through the development of regulations regarding the sale price of salt at salt farmers level ". Minapolitan development strategy for Pati is to "promote technological innovation to anticipate the production of salt in the condition weather anomalies". The strategy formulated for the advanced minapolitan is "improving storage facilities and a system of warehouse receipts, supervision on the entry of imported salt, set clear standards of salt quality and overseeing the base price of salt to match with government regulations".

Keywords: strategy, development, minapolitan area, community salt business institutions.

\section{PENDAHULUAN}

Kondisi produksi garam nasional saat ini cukup rendah dan tidak mampu untuk memenuhi kebutuhan garam nasional. Produksi garam baru mencapai 1.265.600 ton, sedangkan kebutuhannya 2.865 .680 ton. Untuk memenuhi kekurangan tersebut, Indonesia harus mengimpor sebanyak 1.600 .000 ton (Jati dan Purwoko, 2009).

Garam merupakan salah satu potret ironis industri Indonesia, disatu sisi sebagai negara bahari dengan potensi garam, namun disisi lain garam yang dihasilkan sangat rendah. Luas lahan tambak garam nominatif seluas 37.463 hektar dan lahan yang produktif 19.889 hektar $(53,08 \%)$, berarti ada lahan tambak garam seluas 17.574 hektar $(46,92 \%)$ yang tidak dimanfaatkan (A2PGRI, 2009). Berdasarkan kondisi tersebut maka pada tanggal 29 Desember 2009 di Pamekasan (Madura), Menteri Kelautan dan Perikanan meluncurkan program swasembada garam tahun 2015. Berdasarkan Keputusan Menteri Kelautan No. 32 Tahun 2010 Kementrian Kelautan dan Perikanan membuat kebijakan Minapolitan dengan menetapkan 41 lokasi percontohan pengembangan kawasan minapolitan (Anonim, 2011). Sebanyak 24 kabupaten/kota untuk perikanan budidaya, 9 kabupaten/ kota untuk perikanan tangkap dan 8 kabupaten/ kota untuk garam (Grahadyarini, 2010). Berdasarkan realita kebutuhan garam tersebut, maka Kementrian Kelautan dan Perikanan merencanakan swasembada garam tahun 2015.

Suatu hal penting yang perlu ditindaklanjuti dengan segera adalah adanya permasalahan terkait dengan konstelasi tata niaga garam, khususnya posisi tawar (bargaining position). Komunitas petambak garam yang sangat lemah disebabkan belum dimilikinya lembaga representatif yang solid dan kuat serta benar-benar memperjuangkan kepentingan petambak garam. Petambak garam secara individual lemah baik dari kualitas pendidikan dan kemampuan permodalan. Hal ini diperparah dengan sulitnya akses petambak garam terhadap lembaga pembiayaan atau perbankan, informasi pasar dan teknologi.

Tata niaga garam tidak terlepas dari 3 (tiga) hal pokok yang sering menjadi masalah bagi petambak garam, yaitu harga, mutu, dan distribusi produk. Harga ditingkat petambak garam masih bergantung pada mekanisme pasar, belum adanya standarisasi mutu yang disepakati stakeholder terkait, sangat merugikan petambak garam. Selain itu, kenyataaan di lapangan menunjukkan upaya pengembangan garam terkendala oleh regulasi, alur tata niaga, permodalan, kelembagaan dan ketersediaan infrastruktur yang sangat terbatas (Syafii, 2006; Efendi, 2010). 
Fasilitas produksi petambak garam yang masih tradisional ditambah ketersediaan dan kualitas infrastruktur yang kurang memadai, menimbulkan biaya tinggi terutama biaya penanganan dan pengangkutan. Keterbatasan modal juga menyebabkan petambak garam sulit berinvestasi teknologi untuk memperbaiki produktivitas dan mutu serta minimalisasi. Oleh karena itu, diperlukan sebuah rumusan strategi implementasi pengembangan kawasan minapolitan berbasis usaha pegaraman agar tujuan program minapolitan dapat diwujudkan dengan harapan dapat meningkatkan kesejahteraan petambak garam.

Minapolitan merupakan manajemen ekonomi kawasan berbasis komoditas perikanan unggulan dengan fokus pelaksanaannya di daerah. Setiap kawasan terdiri dari sentra produksi terintegrasi dari hulu ke hilir. Persyaratan yang wajib dimiliki daerah antara lain rencana induk minapolitan, penetapan lokasi dan komoditas unggulan, kelompok kerja antar dinas, infrastruktur dasar dan keamanan (BBRSEKP, 2010). Pada pelaksanaannya program minapolitan ini terdapat kelemahan yaitu lemahnya komitmen pemerintah daerah dalam mendukung program ini. Pemetaan ini dikembangkan dari hasil kajian model minapolitan yang dilakukan oleh Balai Besar Riset Sosial Ekonomi tahun 2010. Pada tahun 2010 dilakukan kajian tentang peran dari subsistem tersebut dalam pengembangan minapolitan produk kelautan. Model minapolitan, merupakan model minapolitan yang dibangun berdasarkan 5 (lima) aspek yang disebutkan diatas. Berdasarkan hal tersebut, dalam rangka mengembangkan minapolitan berbasis usaha pegaraman di berbagai kawasan potensial dibutuhkan informasi sosial ekonomi dan strategi pengembangan kawasan minapolitan berbasis usaha pegaraman.

\section{METODOLOGI}

\section{Lokasi dan Waktu Penelitian}

Kegiatan penelitian dilakukan selama 7 bulan (April-Oktober 2011). Lokasi kegiatan merupakan sentra produksi garam di beberapa propinsi ditetapkan sebagai lokasi minapolitan berdasarkan Keputusan Menteri Kelautan dan Perikanan No. 32 tahun 2010 meliputi Cirebon, Indramayu, Pati, Rembang, Brebes, Demak, Jepara, Pasuruan, Lamongan, Sampang, Bangkalan, Pamekasan, Sumenep, Karangasem, Bima, Nagakeo, Takalar, Jeneponto dan Pangkajene kepulauan

\section{Pendekatan dan Metoda Analisis}

Penelitian ini dilakukan menggunakan pendekatan analisis kebijakan, yaitu suatu bentuk kegiatan yang menghasilkan dan menyajikan informasi sedemikian rupa sehingga dapat memberi landasan dari para pembuat kebijakan dalam membuat keputusan (Dunn, 2000). Dalam hal ini, termasuk di dalamnya kegiatan mensitesis dan evaluasi informasi,termasuk hasil-hasil penelitian, untuk akhirnya menghasilkan rekomendasi opsi desain kebijakan publik (Simatupang, 2003).

Data yang dikumpulkan pada kegiatan penelitian ini berupa data primer maupun data sekunder. Data primer yang dikumpulkan adalah informasi tentang berbagai variabel sosial ekonomi pada seluruh aspek generik kawasan minapolitan. Data sekunder yang dapat dikumpulkan antara lain laporan hasil penelitian dan atau kajian yang terkait dengan berbagai aspek yang merupakan dasar kajian strategi pengembangan minapolitan. Kumpulan data tersebut diperlukan dalam rangka merumuskan pemetaan model pengembangan minapolitan berbasis usaha pegaraman.

Teknik pengumpulan data yang dipilih pada kegiatan penelitian ini dilakukan melalui studi pustaka dan survei terstruktur menggunakan panduan kuesioner. Kuesioner yang dipersiapkan dikembangkan dari topik data. Berdasarkan data yang diperoleh dilakukan penilaian (scoring), yang selanjutnya diketahui bahwa berdasarkan scoring tersebut dihasilkan nilai indeks kesiapan pelaksanaan minapolitan yang kemudian dapat diklasifikasikan menjadi kategori kawasan minapolitan perintis, pemula, maju dan 
mandiri. Perumusan strategi pengembangan kawasan minapolitan perikanan berbasis usaha pegaraman dianalisis dengan menggunakan metode SWOT (Sianipar dan Entang, 2008). Tabulasi dilakukan sesuai dengan kebutuhan matrik analisis SWOT yaitu pengelompokan data berdasarkan kategori faktor eksternal dan internal.

Faktor eksternal terdiri atas data dan informasi yang terkait dengan peluang (O) dan ancaman $(T)$, sementara faktor internal terdiri atas informasi yang terkait dengan kekuatan (S) dan kelemahan (W). Model pemetaan pengembangan kawasan minapolitan dihasilkan melalui data primer dan sekunder yang dianalisis dan diformulasikan dengan bantuan software ARC-VIEWS GIS 3.3 untuk menghasilkan Peta Klasifikasi Kesiapan Program Minapolitan Berbasis Usaha Pegaraman di Indonesia,dan Peta Strategi Peningkatan Kesiapan Pelaksanaan Minapolitan Berbasis Usaha Pegaraman.

Penilaian kesiapan suatu daerah dalam pelaksanaan minapolitan berbasis usaha pegaraman didasarkan pada karakteristik sosial ekonomi petambak garam yang menjadi responden penelitian terhadap kondisi berbagai aspek generik dalam penerapan minapolitan yaitu aspek infrastruktur, aspek kelembagaan, aspek masyarakat dan bisnis, aspek sumberdaya dan tata ruang dan aspek kebijakan dan tata kelola pemerintah. Empat kategori lokasi berdasarkan nilai indeks kesiapan pelaksanaan minapolitan dari masing-masing lokasi tersebut adalah sebagai berikut:

\section{Perintis (Nilai Indeks Kesiapan Pelaksanaan Minapolitan (0\%-25\%) )}

Lokasi yang termasuk dalam kategori perintis adalah dengan nilai indeks $0-25 \%$, secara umum dapat dilihat dari sisi infrastruktur masih belum tersedia, kelembagaan yang belum terbentuk, jaringan pemasaran yang belum sempurna, namun memiliki potensi lahan yang belum termanfaatkan secara optimal

\section{Pemula (Nilai Indeks Kesiapan Pelaksanaan Minapolitan (26\%-50\%) )}

Lokasi yang termasuk dalam kategori pemula adalah dengan nilai indeks 26$50 \%$, secara umum masih belum berbeda dengan kondisi pada lokasi perintis namun mulai terlihat keberadaan infrastruktur yang menunjang usaha pegaraman dan juga mulai ada perhatian dari pemerintah daerah setempat tentang potensi pengembangan kawasan minapolitan.

\section{Maju (Nilai Indeks Kesiapan Pelaksanaan Minapolitan (51\%-75\%) )}

Lokasi yang termasuk dalam kategori maju adalah dengan nilai indeks 51-75\%, secara umum dapat dilihat dari infrastruktur yang sudah tersedia, kelembagaan pelaku usaha yang telah terbentuk dan jaringan pemasaran yang sudah melembaga serta lahan potensial yang sebagian besar sudah termanfaatkan. Dukungan pemerintah juga sangat terlihat dengan berbagai kebijakan yang sudah diterapkan namun biasanya belum sampai ke tahap pembentukan masterplan kawasan minapolitan.

\section{Mandiri (Nilai Indeks Kesiapan Pelaksanaan Minapolitan (76-100\%) )}

Lokasi yang masuk dalam kategori mandiri adalah dengan nilai indeks 76-100\%, secara umum terlihat dari kelima aspek generik yang telah memenuhi syarat dan pada kondisi yang optimal serta adanya komitmen daerah yang jelas terhadap pembentukan kawasan minapolitan yang biasanya diikuti dengan pembentukan masterplan. Jaringan kelembagaan dan pemasaran sudah berfungsi dengan baik dan juga telah terlihat adanya investor yang mulai tertarik berinvestasi pada usaha pegaraman. Oleh karena itu daerah yang digolongkan pada kategori mandiri biasanya siap secara swadaya dengan potensi dan upaya sendiri untuk melaksanakan program minapolitan. 


\section{INDEKS KESIAPAN PELAKSANAAN MINAPOLITAN}

Berdasarkan pengukuran indeks kesiapan pelaksanaan minapolitan didapatkan nilai indeks kesiapan pelaksanaan minapolitan sebagai berikut: dari 19 (sembilan belas) lokasi terdapat 2 (dua) lokasi yang dikategorikan sebagai kawasan mandiri, yaitu Kabupaten Pati dan Kabupaten Pamekasan dengan nilai indeks sebesar $80 \%$ dan $85 \%$. Kedua lokasi tersebut merupakan lokasi yang telah ditunjuk sebagai daerah sentra garam rakyat dan memiliki komitmen daerah yang tinggi dalam upaya pelaksanaan program minapolitan berbasis garam. Sementara
17 (tujuh belas) lokasi lainnya (Kabupaten Sumenep, Sampang, Rembang, Indramayu, Cirebon, Nagakeo, Brebes, Demak, Jepara, Pasuruan, Lamongan, Bangkalan, Karangasem, Bima, Takalar, Jeneponto dan Pangkajene Kepulauan) dikategorikan sebagai kawasan maju dalam pelaksanaan minapolitan dengan nilai indeks kesiapan berkisar antara 55\%74\%. Kabupaten Pasuruan memiliki nilai terendah sebesar 55\%, sedangkan Kabupaten Cirebon, Indramayu dan Takalar memiliki nilai terbesar pada kategori maju yaitu sebesar $74 \%$. Nilai indeks kesiapan tersebut diperoleh berdasarkan kondisi rata-rata kesiapan pada tiap aspek generik minapolitan pada lokasi terkait, secara rinci dapat dilihat pada Tabel 1.

Tabel 1. Indeks Kesiapan Pelaksanaan Minapolitan Berbasis Usaha Pegaraman di Lokasi Sentra Garam Tahun 2011.

Table 1. Readiness Index of Minapolitan Implementation Based on Salt Bussiness in Salt Production Area, 2011.

\begin{tabular}{|c|c|c|c|c|c|}
\hline & $\begin{array}{l}\text { Provinsi/ } \\
\text { Province }\end{array}$ & No & $\begin{array}{l}\text { Lokasi/ } \\
\text { Location }\end{array}$ & $\begin{array}{l}\text { Indeks Kesiapan } \\
\text { Minapolitan/ } \\
\text { Minapolitan } \\
\text { Readiness Index (\%) }\end{array}$ & $\begin{array}{c}\text { Kategori Kesiapan } \\
\text { Minapolitan/ } \\
\text { Categories of Readiness } \\
\text { Minapolitan }\end{array}$ \\
\hline \multirow{2}{*}{1} & \multirow{2}{*}{$\begin{array}{l}\text { Jawa Barat/ } \\
\text { West Java }\end{array}$} & 1 & Cirebon & 74 & Maju/Developed \\
\hline & & 2 & Indramayu & 74 & Maju/Developed \\
\hline \multirow{5}{*}{2} & \multirow{5}{*}{$\begin{array}{l}\text { Jawa Tengah/ } \\
\text { Central Java }\end{array}$} & 3 & Pati & 80 & Mandiri/ Self Developed \\
\hline & & 4 & Rembang & 73 & Maju/Developed \\
\hline & & 5 & Brebes & 66 & Maju/Developed \\
\hline & & 6 & Demak & 68 & Maju/Developed \\
\hline & & 7 & Jepara & 72 & Maju/Developed \\
\hline \multirow{6}{*}{3} & \multirow{6}{*}{$\begin{array}{l}\text { Jawa Timur/ } \\
\text { East Java }\end{array}$} & 8 & Pasuruan & 55 & Maju/Developed \\
\hline & & 9 & Lamongan & 66 & Maju/Developed \\
\hline & & 10 & Sampang & 66 & Maju/Developed \\
\hline & & 11 & Bangkalan & 70 & Maju/Developed \\
\hline & & 12 & Pamekasan & 85 & Mandiri/ Self Developed \\
\hline & & 13 & Sumenep & 72 & Maju/Developed \\
\hline 4 & Bali/Bali & 14 & Karangasem & 69 & Maju/Developed \\
\hline 5 & $\begin{array}{l}\text { Nusa Tenggara Barat/ } \\
\text { West Nusa Tenggara }\end{array}$ & 15 & Bima & 71 & Maju/Developed \\
\hline 6 & $\begin{array}{l}\text { Nusa Tenggara Timur/ } \\
\text { East Nusa Tenggara }\end{array}$ & 16 & Nagekeo & 59 & Maju/Developed \\
\hline \multirow{3}{*}{7} & \multirow{3}{*}{$\begin{array}{l}\text { Sulawesi Selatan/ } \\
\text { South Sulawesi }\end{array}$} & 17 & Takalar & 74 & Maju/Developed \\
\hline & & 18 & Jeneponto & 74 & Maju/Developed \\
\hline & & 19 & $\begin{array}{l}\text { Pangkajene } \\
\text { kepulauan }\end{array}$ & 59 & Maju/Developed \\
\hline
\end{tabular}

Sumber: Data Primer (Diolah, 2011) /Source: Primary Data (Process. 2011) 
Tabel 1 menunjukkan bahwa Kabupaten Pati sebagai sentra usaha garam rakyat dengan kategori daerah minapolitan mandiri dibuktikan pula dengan jumlah unit usaha pengolahan garam sebanyak 60 unit usaha pengolahan garam rakyat. Tenaga kerja yang bekerja dalam usaha pengolahan garam adalah 1.444 orang dan 3.511 orang tenaga kerja yang bekerja pada lahan tambak garam.

Luas lahan produksi garam pada Kabupaten Pati berdasarkan keputusan Bupati Pati Nomor 523/049/2011 tahun 2011 mengenai penetapan kawasan Minapolitan garam Kabupaten Pati yaitu sebesar 2.563 hektar dengan rata-rata produksi sebesar 291.968 ton/tahun.

Kabupaten Pamekasan telah siap melaksanakan minapolitan dari aspek kebijakan dan tata kelola pemerintah dengan nilai indeks kesiapan sebesar 99\%. Dokumen tentang tata ruang pengembangan kawasan minapolitan (masterplan) telah terbentuk. Sosialisasi tentang minapolitan telah dilakukan hingga level pembudidaya.
Terdapat dukungan pemerintah daerah terhadap pengembangan kawasan minapolitan. Bentuk dukungan tersebut dalam bentuk SK Bupati tentang penetapan kawasan minapolitan yang telah ada dan sudah disahkan oleh Bupati dengan nomor 188/317/441.131/2010 tentang Penetapan Lokasi Pengembangan Kawasan Minapolitan yang isinya antara lain menetapkan Kecamatan Pademawu dan Kecamatan Galis sebagai Lokasi Kawasan Minapolitan Garam pada Kabupaten Pamekasan, sedangkan lokasi Kawasan Pendukung adalah Kecamatan Tlanakan. Oleh karena itu kedua daerah tersebut dikategorikan mandiri dalam pelaksanaan minapolitan berbasis usaha pegaraman.

Nilai indeks kesiapan pelaksanaan minapolitan berbasis usaha pegaraman pada 19 lokasi penelitian telah diklasifikasikan berdasarkan kategori mandiri, maju, pemula dan perintis yang digambarkan dalam Peta Klasifikasi Kesiapan Program Minapolitan Berbasis Usaha Pegaraman di Indonesia (Gambar 1).

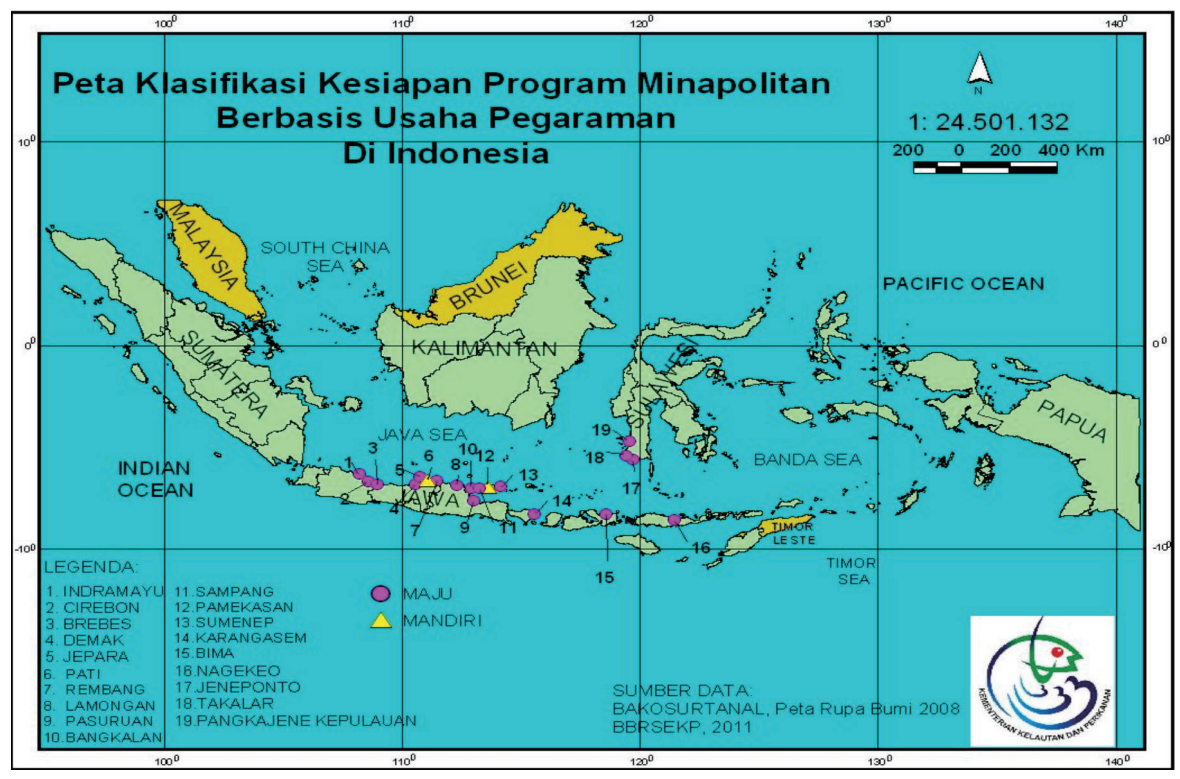

Gambar 1. Peta Klasifikasi Kesiapan Pelaksanaan Minapolitan Berbasis Usaha Pegaraman di Indonesia Tahun 2011.

Figure 1. The Readiness of Map Classifications Minapolitan Based on Community Salt Business in Indonesia, 2011. 
Berdasarkan peta pada Gambar 1 dapat diketahui bahwa daerah yang tergolong mandiri hanya terdapat di dua lokasi yaitu Kabupaten Pamekasan (85\%) dan Kabupaten Pati (80\%). Di dua kabupaten itu, secara umum terlihat dari kelima aspek generik yang telah memenuhi syarat dan pada kondisi yang optimal serta adanya komitmen daerah yang jelas terhadap pembentukan kawasan minapolitan yang biasanya diikuti dengan pembentukan masterplan. Lokasi lainnya masih tergolong kawasan minapolitan maju dengan nilai indeks kesiapan pelaksanaan minapolitan berkisar antara 51\%-75\% secara umum dapat dilihat dari infrastruktur yang sudah tersedia, kelembagaan pelaku usaha yang telah terbentuk dan jaringan pemasaran yang sudah melembaga dan lahan potensial yang sebagian besar sudah termanfaatkan. Dukungan pemerintah juga sangat terlihat dengan berbagai kebijakan yang sudah diterapkan namun biasanya belum sampai ke tahap pembentukan masterplan kawasan minapolitan.

\section{STRATEGI PENGEMBANGAN KAWASAN MINAPOLITAN BERBASIS USAHA PEGARAMAN}

Berdasarkan hasil analisa SWOT yang dilakukan pada enam lokasi penelitian ditambah dengan hasil mail survey pada 13 lokasi penelitian, dapat diklasifikasikan menjadi dua yaitu strategi untuk kawasan minapolitan berbasis usaha pegaraman maju dan strategi untuk kawasan minapolitan berbasis usaha pegaraman mandiri.

\section{Pada Kawasan Pengembangan Minapolitan Katagori Mandiri}

Hasil evaluasi faktor internal ( kekuatan dan kelemahan) dan eksternal (peluang dan ancaman) kawasan minapolitan di Kabupaten Pamekasan berada pada Kuadran III (Gambar 2) sehingga strategi yang dipilih adalah strategi WO atau Weakness Opportunity yang mengoptimalkan peluang yang ada untuk mengatasi kelemahan yang dimiliki. Strategi yang dilakukan adalah "meningkatkan dukungan pemerintah melalui pembuatan regulasi terkait dengan harga jual garam ditingkat petambak garam." Berdasarkan peta posisi Kabupaten Pati dalam penerapan minapolitan berada pada Kuadran IV (Gambar 3) sehingga strategi yang paling sesuai adalah strategi WT atau Weakness Threats yaitu meminimalkan kelemahan untuk menghadapi ancaman, maka strategi yang dilakukan adalah "tingkatkan inovasi teknologi produksi garam untuk mengantisipasi anomali cuaca".

\section{Pada Kawasan Pengembangan Minapolitan Katagori Maju}

Hasil evaluasi faktor internal (kekuatan dan kelemahan) dan faktor eksternal (peluang dan ancaman), diketahui bahwa peta posisi pengembangan kawasan minapolitan katagori maju berada pada Kwadran II (Gambar 4) yaitu strategi ST, yaitu mengoptimalkan kekuatan untuk menghadapi ancaman sehingga strategi yang dipilih adalah" memperbaiki fasilitas penyimpanan dan pemberlakuan sistem resi gudang, melakukan pengawasan ketat terhadap masuknya garam impor, tetapkan standar kualitas garam yang jelas dan awasi harga dasar garam agar sesuai peraturan yang ditetapkan pemerintah".

Strategi yang telah dihasilkan oleh analisis SWOT ditindaklanjuti dengan implikasi strategi yang merupakan langkah operasional yang dapat diterapkan sesuai dengan kategori kawasan minapolitan yang telah diklasifikasikan/dikemukakan pada Tabel 2 dan 3.

Berdasarkan analisis SWOT, penetapan strategi peningkatan kesiapan pelaksanaan minapolitan usaha pegaraman dilakukan pada enam lokasi penelitian ditambah dengan hasil mail survey pada 13 lokasi penelitian dapat diklasifikasikan menjadi dua yaitu strategi untuk kawasan minapolitan berbasis usaha pegaraman maju dan strategi untuk kawasan minapolitan berbasis usaha pegaraman mandiri. 


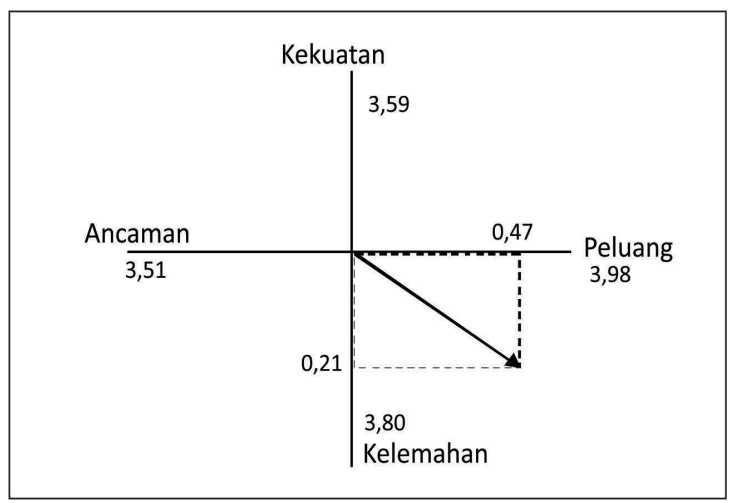

Gambar 2. Peta Posisi Kekuatan Kabupaten Pamekasan dalam Penerapan Minapolitan berbasis Usaha Pegaraman.

Figure 2. Map of Pamekasan District Strenght Position in Minapolitan Based on Salt Bussiness Implementation.

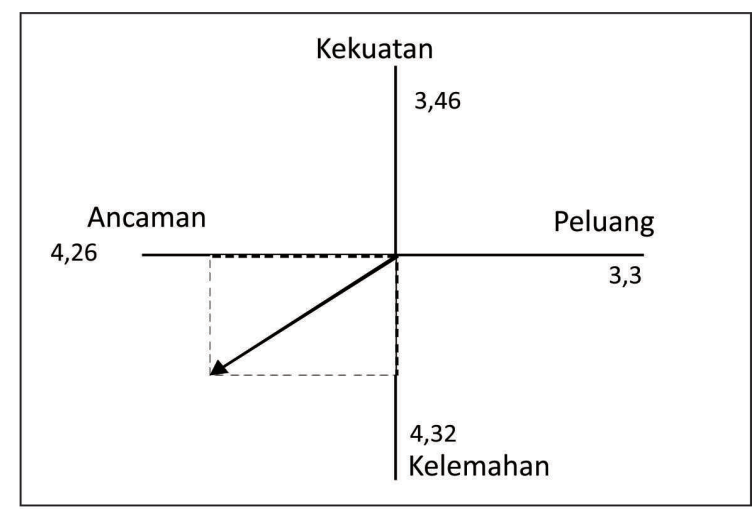

Gambar 3. Peta Posisi Kekuatan Kabupaten Pati dalam Penerapan Minapolitan Berbasis Usaha Pegaraman.

Figure 3. Map of Pati District Strenght Position in Minapolitan Based on Salt Bussiness Implementation.

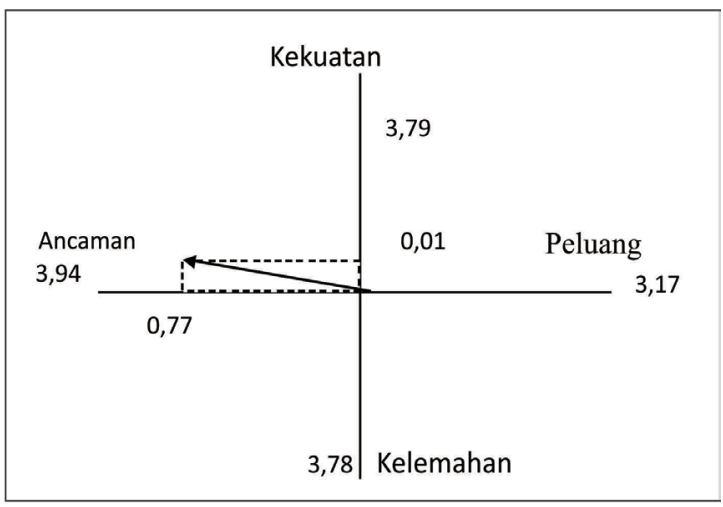

Gambar 4. Peta Posisi Kekuatan Kategori Maju dalam Penerapan Minapolitan Berbasis Usaha Pegaraman.

Figure 4. Map of Strenght Position Clasifed as Developed in Minapolitan Based on Salt BussinessImplementation. 
Tabel 2. Strategi dan Implikasi Strategi Pengembangan Kawasan Minapolitan Berbasis Usaha Pegaraman pada Kawasan Minapolitan Maju Tahun 2011.

Table 2. Strategies and Implications for Development Strategy Minapolitan based on Community Salt Business at the Area of Minapolitan Maju, 2011.

\begin{tabular}{|c|c|}
\hline No & Strategi/Strategy \\
\hline 1 & $\begin{array}{l}\text { Perbaiki fasilitas penyimpanan } \\
\text { dan pemberlakuan sistem resi } \\
\text { gudang/ Improve storage } \\
\text { facilities and the enactment } \\
\text { of the warehouse receipt } \\
\text { system. }\end{array}$ \\
\hline 2 & $\begin{array}{l}\text { Tetapkan standar kualitas } \\
\text { garam yang jelas dan awasi } \\
\text { harga dasar agar sesuai } \\
\text { peraturan yang ditetapkan } \\
\text { pemerintah/ Set of standards } \\
\text { of quality salt clear and } \\
\text { supervise basic price to fit } \\
\text { regulation determined by the } \\
\text { government. }\end{array}$ \\
\hline
\end{tabular}

3 Pemerintah harus menetapkan dan menerapkan kebijakan kemudahan akses permodalan agar produksi garam berkualitas tetap dapat dilakukan/The Government must establish and implement a policy of easy access to capital remains quality salt production can be done.

\begin{abstract}
Pemerintah daerah memfasilitasi gudang penyimpanan permanen dengan pemberlakuan sistem resi gudang/ Local Governments facilitate permanent storage with the enactment of the warehouse receipt system.
\end{abstract}

1. Pemerintah mengembangkan alat pengukur kualitas garam yang dapat digunakan dan diperoleh dengan mudah oleh petambak garam sehingga dapat meningkatkan posisi tawar mereka dalam penentuan harga garam/ The government develops gauge the quality of salt that can be used by farmers and exploited easily salt so as to strengthen bargaining position of them in the determination of the price of salt.

2. Pembuatan regulasi terkait dengan sanksi yang diberlakukan apabila harga yang berlaku dibawah harga dasar yang sudah ditetapkan/ The making of regulations related to the sanctions imposed when the price goes below the base price has been set.

1. Pemerintah meningkatkan infrastruktur dan distribusi produksi garam/ The Government improve infrastructure and distribution of salt production.

2. Pemerintah memfasilitasi gudang yang permanen dengan pemberlakukan resi gudang/ The Government facilitated the permanent warehouse with warehouse receipt system.

3. Pemerintah memberlakukan regulasi terkait dengan sanksi yang berlaku bila terjadi harga jual dibawah harga dasar pemerintah/ The Government enacted the regulation related to the applicable sanctions when there selling price under the Government's base price.

4. Akses permodalan untuk pengolahan lahan tambak garam melalui koperasi dan bank/ Access to capital for processing farm ponds of salt through cooperatives and banks.

4 Tingkatkan teknologi pegaraman untuk mengatasi anomali cuaca melalui penambahan modal petambak garam /Increase Salt of technology to overcome the weather anomaly through capital increase farmers salt.
1. Penyediaan pembangunan gudang permanen untuk penyimpanan garam/ The provision of the construction of a

2. Mempermudah mendapatkan akses permodalan bagi usaha pergaraman/ Facilitate access to venture capital Community Salt Business Institutions.

3. Alternatif teknologi pergaraman pengganti matahari sebagai sumber panas/ Alternative Salt of Technology replacement for the Sun as heat source. permanent storage warehouse to a salt. 
Tabel 3. Strategi dan Implikasi Strategi Pengembangan Kawasan Minapolitan Berbasis Usaha Pegaraman pada Kawasan Minapolitan Mandiri Tahun 2011.

Table 3. Strategies and Implications for Development Strategy Minapolitan Based on Community Salt Business at the Area of Minapolitan Mandiri, 2011.

\begin{tabular}{|c|c|c|}
\hline No & Strategi/Strategy & $\begin{array}{c}\text { Implikasi Strategi/ } \\
\text { Implication of Strategy }\end{array}$ \\
\hline \multirow[t]{2}{*}{1} & $\begin{array}{l}\text { Tingkatkan dukungan pemerintah } \\
\text { dengan pembuatan regulasi atau } \\
\text { pembentukan lembaga keuangan } \\
\text { mikro yang dapat diakses oleh } \\
\text { petambak garam/ Increase the support }\end{array}$ & $\begin{array}{l}\text { 1. Dibentuk lembaga permodalan untuk } \\
\text { mempermudah mengakses modal melalui } \\
\text { koperasi maupun bank/ Formed institution } \\
\text { capital to facilitate access capital through } \\
\text { cooperative and bank. }\end{array}$ \\
\hline & $\begin{array}{l}\text { of government by the manufacture } \\
\text { regulation or the formation of micro } \\
\text { finance institution accessible to farmers } \\
\text { salt. }\end{array}$ & $\begin{array}{l}\text { 2. Pemerintah membuat regulasi terkait dengan } \\
\text { sanksi yang berlaku apabila terjadi harga } \\
\text { jual dibawah harga dasar pemerintah/ The } \\
\text { Government made regulation related to the } \\
\text { sanctions applicable in the event of selling price } \\
\text { under the base price of the government. }\end{array}$ \\
\hline \multirow[t]{2}{*}{2} & $\begin{array}{l}\text { Tingkatkan inovasi teknologi dalam } \\
\text { usaha pegaraman untuk mengantisipasi } \\
\text { anomali cuaca/Increase technological } \\
\text { innovations in an attempt to anticipate } \\
\text { Community Salt Business Institutions } \\
\text { the anomaly lay in the weather. }\end{array}$ & $\begin{array}{l}\text { 1. Membuat alternatif teknologi pengganti } \\
\text { dengan menggunakan teknik evaporasi selain } \\
\text { menggunakan sinar matahari sebagai sumber } \\
\text { panas/ Make alternative technology substitute } \\
\text { using technique evaporative only using sunlight } \\
\text { as a source of heat. }\end{array}$ \\
\hline & & $\begin{array}{l}\text { 2. Diseminasi teknologi tepat guna pencucian } \\
\text { garam/ The dissemination of appropriate } \\
\text { technology to the leaching of salt. }\end{array}$ \\
\hline
\end{tabular}

Sumber: Data Primer (Diolah, 2011)/Source: Primary Data (Process, 2011)

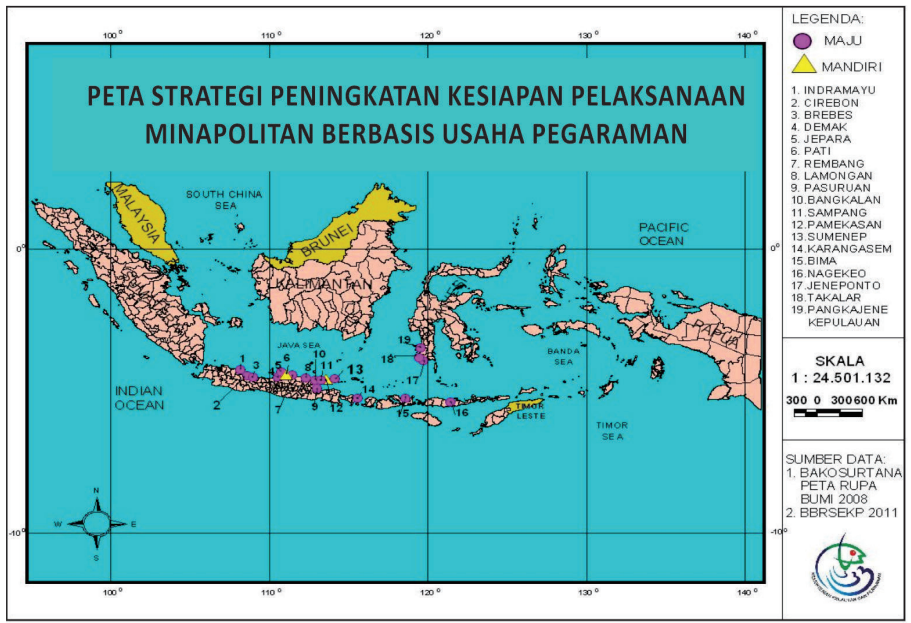

\begin{tabular}{|l|}
\hline Strategi untuk daerah MAJU: \\
1. Perbaiki fasilitas penyimpanan dan \\
pemberlakuan sistem resi gudang \\
2. Tetapkan standar kualitas garam yang jelas \\
dan awasi harga dasar agar sesuai per- \\
aturan yang ditetapkan pemerintah \\
3. Pemerintah harus menetapkan dan \\
menerapkan kebijakan kemudahan akses \\
permodalan agar produksi garam berkuali- \\
tas tetap dapat dilakukan \\
4. Tingkatkan teknologi pegaraman untuk \\
mengatasi anomali cuaca melalui penam- \\
bahan modal petambak garam \\
STRATEGI UNTUK DAERAH MANDIRI: \\
1. Tingkatkan dukungan pemerintah dengan \\
pembuatan regulasi atau pembentukan \\
lembaga keuangan mikro yang dapat diak- \\
ses oleh petambak garam \\
2. Tingkatkan inovasi teknologi dalam usaha \\
pegaraman untuk mengantisipasi anomali \\
cuaca.
\end{tabular}

Gambar 5. Peta Strategi Peningkatan Kesiapan Pelaksanaan Minapolitan Berbasis Usaha Pegaraman Tahun 2011.

Figure 5. Amap of the increase in the Implementation of the Strategy of Readiness Minapolitan Based on Community Salt Business Institutions, 2011. 
Strategi peningkatan kesiapan pelaksanaan minapolitan berbasis usaha pegaraman tersebut dijelaskan pada peta berikut:

\section{REKOMENDASI DAN LANGKAH STRATEGIS}

1. Strategi pengembangan program minapolitan berbasis usaha pegaraman pada katagori mandiri adalah :

a. Menjaga harga garam ditingkat petambak garam sesuai dengan harga dasar yang ditetapkan oleh pemerintah.

b. Membentuk Badan Pengelola Garam sebagai upaya untuk menjamin harga garam ditingkat petambak garam sesuai dengan harga yang sudah ditetapkan oleh pemerintah sehingga posisi tawar petambak garam terkait dengan penentuan harga garam menjadi lebih besar.

c. Membuat alternatif teknologi yang dapat meningkatkan kualitas dan kuantitas garam, mencakup teknologi evaporasi semi mekanis pada tahapan produksi garam, sehingga tidak hanya mengandalkan teknologi evaporasi secara alami dengan menggunakan tenaga surya serta penambahan zat aditif yang aman. Selain itu juga perlu adanya sosialisasi dan introduksi teknologi pencucian garam.

2. Strategi pengembangan program minapolitan berbasis usaha pegaraman pada katagori maju adalah :

a. Memfasilitasi gudang penyimpanan garam permanen, sehingga garam yang disimpan oleh petambak dapat dijadikan jaminan, apabila petambak garam memerlukan modal untuk perbaikan lahan tambak garam dan pembelian peralatan produksi. Petambak garam dapat menyimpan garam hasil produksinya dan dapat dijual pada saat belum atau tidak panen, sehingga harga garam menjadi lebih tinggi. Sistem resi gudang disini adalah dokumentasi/ surat bukti kepemilikan barang yang disimpan di gudang, diterbitkan oleh pengelola gudang tertentu, dan harus mendapatkan persetujuan dari Badan Pengawas Perdagangan Berjangka Komoditi (BAPPEBTI), salah satu unit esselon I di Kementrian Perdagangan. Pembuatan resi gudang ini dilakukan berdasarkan pada ketentuan Peraturan Menteri Keuangan Nomor 171/PMK.05/2009 tentang Skema Subsidi Resi Gudang (SRG) dan Peraturan Menteri Perdagangan Nomor 66/M-DAG/PER/12/2009 tentang Pelaksanaan Skema Subsidi Resi Gudang. Surat ini nantinya dapat dijadikan sebagai jaminan/agunan apabila petambak garam ataupun KUGAR mengakses pinjaman modal ke bank.

b. Mensosialisasikan dan mengembangkan alat pengukur kualitas garam yang dapat digunakan dan diperoleh dengan mudah oleh petambak garam. Sosialisasi dilakukan oleh Pemerintah dalam hal ini adalah Kementrian Perindustrian dan Perdagangan, sehingga dapat meningkatkan posisi tawar petambak garam dalam penentuan harga garam.

c. Membuat regulasi terkait dengan sangsi yang diberlakukan apabila harga garam yang berlaku ditingkat petambak garam berada dibawah harga dasar yang sudah ditetapkan oleh pemerintah.

\section{PENUTUP}

Indeks kesiapan lokasi penelitian sentra garam terdiri dari 2 (dua) kategori, yaitu kategori maju dan mandiri. Kesiapan penggunaan lahan yang masih rendah adalah Brebes, Bangkalan, Indramayu dan Sampang, sedangkan lokasi lainnya pemanfaatan lokasi sudah mencapai $75 \%$. 
Daerah yang tergolong mandiri hanya terdapat di dua lokasi yaitu Kabupaten Pamekasan (85\%) dan Kabupaten Pati (80\%). Lokasi yang tergolong Kawasan Minapolitan Maju dengan nilai indeks kesiapan pelaksanaan minapolitan berkisar antara 51\%-75\% adalah Kabupaten Sumenep, Sampang, Rembang, Indramayu, Cirebon, Nagakeo, Brebes, Demak, Jepara, Pasuruan, Lamongan, Bangkalan, Karangasem, Bima, Takalar, Jeneponto dan Pangkajene Kepulauan.

Langkah operasional penerapan strategi pengembangan minapolitan usaha pegaraman untuk kategori mandiri adalah :

1. Menjaga stabilitas harga garam ditingkat petambak garam sesuai dengan harga dasar yang ditetapkan oleh pemerintah.

2. Membentuk Badan Pengelola Garam sebagai upaya untuk menjamin harga garam ditingkat petambak garam sesuai dengan harga yang sudah ditetapkan oleh pemerintah sehingga posisi tawar petambak garam terkait dengan penentuan harga garam menjadi lebih besar.

3. Membuat alternatif teknologi yang dapat meningkatkan kualitas dan kuantitas garam, mencakup teknologi evaporasi semi mekanis pada tahapan produksi garam dan teknologi pencucian garam krosok.

Langkah operasional penerapan strategi pengembangan minapolitan usaha pegaraman untuk kategori majui adalah :

1. Memfasilitasi gudang penyimpanan garam permanen, sehingga garam yang disimpan oleh petambak dapat dijadikan jaminan, apabila petambak garam memerlukan modal untuk perbaikan lahan tambak garam dan pembelian peralatan produksi.

2. Mensosialisasikan dan mengembangkan alat pengukur kualitas garam yang dapat digunakan dan diperoleh dengan mudah oleh petambak garam. Sosialisasi dilakukan oleh Pemerintah dalam hal ini adalah Kementrian Perindustrian dan Perdagangan, sehingga dapat meningkatkan posisi tawar petambak garam dalam penentuan harga garam.

3. Membuat regulasi terkait dengan sangsi yang diberlakukan apabila harga garam yang berlaku ditingkat petambak garam berada dibawah harga dasar yang sudah ditetapkan oleh pemerintah.

\section{DAFTAR PUSTAKA}

Anonim. 2011. Surat Keputusan Menteri Kelautan dan Perikanan No. 32 Tahun 2010 Tentang Penetapan Kawasan Minapolitan. Kementerian Kelautan dan Perikanan. Jakarta.

. 2011. Data Impor Garam Indonesia. Pusat Data dan Informasi Kementerian Perdagangan. Jakarta.

Dunn, W.N. 2000. Pengantar Analisis Kebijakan Publik. Edisi Kedua. Gajah Mada University Press. Yogyakarta.687p.

Efendi, M. 2009. Garam Madura. Universitas Trunojoyo. Bangkalan-Madura.

Grahadyarini. 2010. Apa Kabar Program Minapolitan. Kompas, Kamis, 21 Oktober 2010.

Jati dan Purwoko. Indonesia Miskin Garam. Bisnis Indonesia.

Sianipar, J.P.G dan Entang, H.M. 2008. Teknik-Teknik Analisis Manajemen. Modul Pendidikan dan Pelatihan Kepemimpinan Tingkat III. Lembaga Administrasi Negara - Republik Indonesia. Jakarta.

Simatupang, P. 2003. Analisis Kebijakan : Konsep Dasar dan Prosedur Pelaksanaan. Analisis Kebijakan Pertanian. I (1): 14-35. Pusat Penelitian dan Pengembangan Sosial Ekonomi Pertanian. Badan Penelitian dan Pengembangan Pertanian. Departemen Pertanian.

Syafii, A. 2006. Potret Pemberdayaan Petani Garam. Implementasi Konsep dan Strategi. Universitas 17 Agustus 1945 Surabaya. 